\title{
“CLAPARÈDE, MESTRE E AMIGO”: MEMÓRIAS DE TRAVESSIAS
}

\author{
Ana Chrystina Mignot \\ Universidade do Estado do Rio de Janeiro/ Procientista \\ Pesquisadora do CNPq/ Cientista de Nosso Estado - FAPERJ/
}

\section{Resumo}

A Associação Brasileira de Educação (ABE), que congregou, a partir de 1924, intelectuais de diversas áreas com finalidade de traçar ação política em favor da causa da educação nacional, guarda uma pasta, de 1973, denominada Claparède, mestre e amigo. Seus documentos foram preservados por Laura Jacobina Lacombe, educadora católica que teve atuação destacada no debate educacional a partir da divergência com os pioneiros, em 1932. Ali estão memórias de quando estudou no Instituto Jean-Jacques Rousseau, na Suiça, em 1925 e 1927. Ali fabricou-se uma nova sensibilidade pela infância que orientou a defesa da escola como direito das crianças e a necessidade de assegurar métodos de ensino renovadores. Busco interpretar pistas de como a educadora se apropriou das propostas escolanovistas que lhe serviriam, posteriormente, à produção e difusão do discurso educacional católico.

Palavras-chave: Viagens pedagógicas, Laura Jacobina Lacombe, Edouard Claparède Associação Brasileira de Educação, Instituto Jean-Jacques Rousseau.

\section{“CLAPAREDE, MASTER AND FRIEND": crossing memories}

\begin{abstract}
The Brazilian Association of Education (ABE) which has, since 1924, gathered together intellectuals from sundry areas so as to trace political actions favoring national education, save a document file of 1973 named Claparède, master and friend. The documents were preserved by Laura Jacobina Lacombe, Catholic educator who had outstanding performance in educational debate from the divergence with the pioneers, in 1932. They contain memories of when she studied at the Institut Jean-Jacques Rousseau, in Switzerland, in 1925 and 1927. The institute created a new sensibility for infancy which defended the school as a child's right and the need to assure renewable teaching methods. In this paper I attempt to interpret indications of just how the educator made use of new school proposals which later served for the production and diffusion of the catholic educational discourse.
\end{abstract}

Key Words: Pedagogical trips, Laura Jacobina Lacombe, Edouard Claparede, the Brazilian Association of Education, the Jean-Jacques Rousseau Institute.

\section{“CLAPARÈDE, MESTRE E AMIGO”: MEMÓRIAS DE TRAVESSIAS}

Repleta de fotografias, recortes de jornais, prospectos, um texto datilografado, cópias de cartas e bilhetes, uma pasta que repousa nas prateleiras de armários escuros da Associação Brasileira de Educação (ABE) instiga a curiosidade dos pesquisadores que recorrem ao acervo da entidade que, a partir de 1924, congregou intelectuais de diversas áreas com a finalidade de traçar a ação política em favor da causa da educação nacional, pois os documentos foram cuidadosamente preservados por Laura Jacobina Lacombe, uma educadora católica que teve 
atuação destacada no debate educacional tanto na $\mathrm{ABE}$ quanto a partir da divergência com os pioneiros, em 1932. Datada de 1973, produzida para a sessão comemorativa do centenário de nascimento de Edouard Claparède, promovida pela associação, em julho daquele ano.

Muitos anos se passaram entre o período registrado naqueles velhos papéis e o ano em que Laura doou a documentação. Já não era mais a jovem vice-diretora do Colégio Jacobina, de quando chegou a ABE. Ao longo do tempo, integrou a direção da Associação de Professores Católicos do Distrito Federal, criada em 1931, entidade que, segundo Bernadete de Lourdes Streisky Stang tinha por missão "fomentar a verve religiosa do professorado e prestar esclarecimento sobre a Escola Nova, mostrando até que ponto era aceitável e que parte dela precisava ser avaliada" (2008, p. 67), e presidiu, a partir de 1956, a Organização Mundial de Educação Pré-Escolar no Brasil (OMEP), que reuniu várias lideranças católicas, realizando o primeiro levantamento da educação pré-escolar do país. Publicara três livros: Moral cristã e educação (1936), A escola e a vida (1942) e Como nasceu o Colégio Jacobina (1962).

Naquela pasta estão documentos muito diferentes dos demais do período no qual participou da Seção de Cooperação da Família, na qual teve um relevante papel junto a Armanda Alvaro Alberto, Corina Barreiros, Ana Amélia Queiroz Carneiro de Mendonça, Miss Myrth King, Miss Eva Hyde, Carlotita Lyra e Silva, dentre outras mulheres católicas e protestantes, militantes de associações femininas e feministas, que se colocaram como guardiãs da nação, ao se valeram de ideias educacionais estrangeiras, especialmente suíças e belgas, que chegavam através de livros, jornais, revistas e prospectos, fundamentando as propostas por elas delineadas, e em particular, a produção e difusão de uma série de recomendações e prescrições sobre a leitura infantil. ${ }^{\mathrm{i}}$ Também, não tratam do forte debate travado entre católicos e pioneiros, após a saída da entidade do grupo do qual fazia parte ${ }^{\mathrm{ii}}$, em virtude dos pontos de vista opostos aos princípios proclamados pelo Manifesto dos Pioneiros da Educação Nova (1932). A pasta intitulada "Claparède, mestre e amigo" contém memórias de viagens pedagógicas, particularmente, as que realizou à Suiça, em 1925 e 1927, quando estudou no Instituto JeanJacques Rousseau e representou a ABE no Congresso Internacional de Educação Moderna, em Locarno, mas, também, da vinda do educador ao Brasil, em 1930. Considerando-as como parte das estratégias daquele instituto, no momento de fabricação de uma nova sensibilidade pela infância que orientou a defesa da escola como direito das crianças e a necessidade de assegurar métodos de ensino renovadores, busco interpretar, nestes velhos papéis, pistas de como a educadora se apropriou das propostas escolanovistas que lhe serviriam, posteriormente, à produção e difusão do discurso educacional católico. 


\section{Uma viajante de muitas travessias}

Também se passaram muitos anos da primeira vez que estive com esta pasta nas mãos. Ao me voltar para a viagem da Antonia Ribeiro de Castro, uma educadora campista, mapeei algumas das mulheres reunidas na ABE que atravessaram o Atlântico em busca de formação. Não me passou despercebida a participação de Laura Jacobina Lacombe ao Congresso Mundial de Educação Moderna, de Locarno, em 1927, quando representou a entidade no evento. Em meio à documentação consultada, na entidade, se destacou um conjunto de documentos manuscritos, datilografados e xerocopiados por ela reunidos, em 1973, que relatam sua amizade com E. Claparède, desde a viagem feita em 1925:

Faz quase cinquenta anos, recebemos boa acolhida nas salas do 'Institut Jean Jacques Rousseau', que frequentávamos o 'Vieux Champel', onde se achava a mansão em que residia o Professor Claparède, em cujo parque fervilhava a alegria da 'Maison des Petits'. Éramos uns trinta e seis alunos de quatorze países diferentes, todos cativados pelo acolhimento dos mestres Bovet e Claparède que, unidos como dois irmãos, realizaram, felizes, o seu sonho de renovação da pedagogia. (Meireles, 1930, p. 6)

O destino escolhido permitiu o contato com os principais grupos articulados em torno dos cientistas e educadores que lideraram a produção e difusão de ideário pedagógico renovador: A. Ferrière, P. Bovet, E. Claparède, em Genebra, e O. Decroly, em Bruxelas, que, segundo Lourenço Filho, a partir da escola L'Ermitage, defendia os centros de interesses, o que exigia "necessariamente (...) imprimir nova sequência ao trabalho escolar e ao emprego do tempo ou seja, do horário" (1962, p. 193), o que lhe permitiu expandir suas experiências para as escolas públicas belgas e difundir suas concepções por outros países, especialmente, por suas viagens à Bolívia, Argentina e Uruguai (1915), Espanha (1916) e Estados Unidos (1922). Aliás, o encantamento de Laura com o trabalho por eles realizado constou do relatório apresentado ao Conselho Diretor da $\mathrm{ABE}$, com menção em ata que registra o relato de viagem por ela feito, em reunião de novembro de 1927:

Em seguida, D. Laura Lacombe leu o seu relatório referente à sua ida ao Congresso de Educação realizado em Locarno. Dr. Backeuser pede que um voto de louvor seja inserido na ata pela brilhante atuação de D. Laura Lacombe e pede a publicação de seu relatório. Foi aprovado unanimemente. Ainda o Sr. Backeuser solicita que a ABE se interesse pela Escola Ativa lembrando as vantagens e inconvenientes. D. Armanda A. Alberto lembra que a Escola Regional de Merity já usa o método anteriormente falado. (Ata. ABE, 1927) 
Posteriormente, me dei conta de que estas seriam apenas as primeiras de muitas viagens internacionais feitas por Laura Jacobina Lacombe, pois os estudos de Andrea Caruso (2006) e Silmara de Fátima Cardoso (2015) me permitiram inventariar um conjunto significativo de destinos escolhidos por ela para se aprimorar. Depois que visitara Locarno (1927) para participar do Congresso Internacional de Educação Moderna, promovido pela Ligue Internacional de Educacion Nouvelle, fora a muitas outras cidades: Nova York (1929) como membro da missão de estudos da ABE em estágio no Teacher's College, Bruxelas (1933) para estudar na Université Catholique de Louvain, Veneza e Paris, provavelmente em 1945, como participante do Congresso da Union International Catholique de l'Infance, Bogotá (1945) por ocasião da fundação da Confederação Internacional de Educação Católica, La Paz (1948) onde integrou Comissão de Estudos, Bogotá (sem data) para participar do Seminário Regional de Educação das Organizações Não-Governamentais (ONU), Estrasburgo (1961), e Atenas (1956), Bruxelas (1958), Zagreb (1960), Londres (1962), Estocolmo (1964), Paris (1966), Washigton (1968) e na Alemanha (1970), quando representava o Brasil nas assembleias mundiais da OMEP.

A escolha de Laura, na Associação Brasileira de Educação (ABE), para integrar os grupos de educadores que viajaram sob a chancela da associação, em 1929, pode ser melhor compreendida quando se segue as pegadas deixadas no estudo de Silmara de Fátima Cardoso (op.cit) que se voltou para as missões de educadores aos Estados Unidos, na gestão de Anísio Teixeira, à frente da Diretoria da Instrução Pública do Distrito Federal (1931-1935), o que a obrigou a fazer um breve recuo para examinar o intercâmbio já estabelecido com aquele país, no âmbito da referida associação. Juntamente com Carolina Coelho do Rego Rangel, Consuelo Pinheiro, Otávio B. Couto e Silva, Eunice Caldas, Henry Othon Leonardos, Julieta Arruda, Maria dos Reis Campos e Noemy Silveira Rudolfer, Laura Jacobina Lacombe visitou o Teacher's College de Nova-York, em missão de intercâmbio articulada por Delgado de Carvalho com a Fundação Carnegie Endowement, a União Pan-Americana, o Instituto Internacional de Educação e a Universidade de Colúmbia, viagem amplamente divulgada no Traço de União, por Isabel Jacobina Lacombe:

Está longe de nós, imaginar ter atingido a perfeição, pelo contrário, procuramos sempre melhorar, incitando os exemplos dos grandes centros de cultura, estudando as modificações do ensino moderno. É nesse intento que a $1^{\circ}$ de janeiro deve partir para os Estados Unidos a nossa jovem e intrépida vice-diretora Laura Lacombe, aproveitando a feliz iniciativa da Associação Brasileira de Educação, que promoveu e felicitou essa proveitosa viagem a um grupo de dez professores brasileiros. Vai ela fazer um estágio no Teacher's College em Nova York, em busca de moderna orientação americana e de outras luzes que 
venham enriquecer o tesouro intelectual do Curso Jacobina (Lacombe, 1930, p.2-3, apud Cardoso, 2015, p. 57).

É possível observar, ainda, nos destinos de suas viagens, um deslocamento sistemático e crescente que expressa uma aproximação com as instituições internacionais católicas, logo após

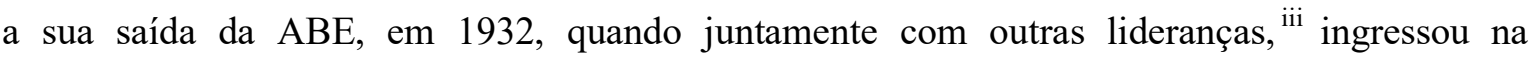
Associação de Professores Católicos do Distrito Federal, entidade que visava aglutinar professores cariocas "com o propósito de discutir problemas pedagógicos e formular propostas de ação" (Caruso, op.cit, p. 56). A entidade cujas atividades se iniciaram em 1931, sob a liderança de Everardo Backheuser e do Padre Leonel Franca, dois anos depois, viria a ser organizada nacionalmente como Confederação Católica Brasileira de Educação, que tinha por objetivo formular uma política de educação fundamentada na doutrina católica.

A partir de 1956, quando ocupa a presidência da Organização Mundial de Educação PréEscolar (OMEP), ${ }^{\text {iii }}$ Laura prossegue em viagens mundo afora, o que lhe permitiu refinar sua concepção de educação baseada no conhecimento da infância proporcionado pela Psicologia e por um ideal de educação católico, unindo ciência e fé. Em discurso proferido por ocasião da modernização dos estatutos da entidade, provavelmente em 1970, ela comentou a importância de suas viagens:

Assim que assumi a presidência, achei necessário integrar-me no movimento da OMEP, comparecendo à Assembleia Mundial, em Atenas (1956).

Como, naquele ano, levei um grupo de alunas à Europa, despedi-me delas em Roma, de onde voltaram ao Brasil com minha assistente, e parti para Atenas.

Compreendi, então como indispensável esse contato com os elementos dos outros países e resolvi que traria para o nosso trabalho no Brasil.

Compareci em diversos Congressos como única representante do Brasil; sempre era interrogada: 'porque não vêm outras professoras do seu país?' Afinal, consegui que D. Nazira Feres Abi-Saber comparecesse a Londres graças ao interesse do Governador Magalhães Pinto.

A Estocolmo, compareceu a Prof ${ }^{a}$ Heloisa Marinho, assim como duas professoras de Brasilia; enfim, a delegação de Paris contou com treze membros. (...)

Talvez algumas pessoas julguem que tenho auferido benefícios no exercício do cargo de Presidente do Comitê Nacional Brasileiro.

Para Zagreb, Londres, e Estocolmo, recebi pequeno auxílio, que deu para cobrir a hospedagem. Para a Assembleia de Paris, não me atrevi a pedir ajuda, sabendo que o Ministro estava financiando a viagem da Presidente de uma das Associações Estaduais.

Só em 1967, graças à boa vontade do Secretário Geral do Itamarati, recebi um auxílio para participar do Seminário de Liège. Esforcei-me por corresponder a tanta confiança que em mim depositaram e fiquei 
satisfeita por ter podido lá relatar realizações e não, apenas, ficar na teoria e no sonho, como muitos.

Como disse acima, as minhas economias são destinadas às minhas viagens e essas têm sempre um objetivo de estudo, de colaboração. Têm sempre sido proveitosas para o meu trabalho na difusão e progresso do ensino pré-primário, como para o Comitê Nacional da OMEP ( LACOMBE, 1970, s/p.)

Ao me voltar para os documentos guardados por Laura, penso que fazem parte de uma certa narrativa de viagens que, como lembra Antonio Viñao Frago (2000), mesmo os autores pouco falando de si, seus relatos funcionam como "testemunho direto do visto, ouvido e vivido" (op.cit. p. 88). O texto escrito em homenagem ao educador orienta a organização de documentos das duas viagens: uma fotografia de Claparède sentado à mesa de trabalho, rodeado de retratos e livros, uma excursão do mestre e alunos ao Monte Salève, um desenho assinado por ele dos alunos escalando a montanha, fotografias nas quais aparece na temporada suíça, legendadas "Reunião em casa do Prof. Claparède", "Ao sair da Universidade", "Na porta do Institut J.-J. Rousseau", "Alunos com os Professores Bovet e Piaget", "Reunião em casa de Mr Claparède 19-III-1925”; e, também, as fotografias de Locarno, em 1927, "L’Education Nouvelle Decroly, Bovet, Mrs Ensor, Claparède, Greheeb, Ferrière", "Satélites em torno de um astro", duas fotografias nas quais está ao lado dos grandes mestres: "Com o Prof. Claparède", "Com o Prof. Ferrière", seguidas de partitura da música dos congressistas, do programa de estudos do curso do Instituto Jean-Jacques Rousseau que se iniciaria em outubro daquele ano, por exemplo, que parecem querer comprovar a veracidade do narrado.

De certo modo, os documentos reunidos contam do significado que as travessias do Atlântico representaram para aprender, experimentar, comparar, fundamentar, enfim, suas concepções e práticas pedagógicas aprendidas em livros e desenvolvidas no âmbito escolar. Se estes foram os objetivos iniciais que a moveram inicialmente, não se furtou de relatar, divulgar, aplaudir, criticar, triar, adaptar, interpretar e propagar o que viu, ouviu, observou, experimentou, viveu.

\section{Relatos de viagens, memórias de formação.}

O tom da narrativa de Laura Jacobina Lacombe no texto que integra a pasta Claparède, mestre e amigo, é de homenagem ao grande educador, mas é sobretudo um modo de deixar marcado a importância que o seu encontro com ele desempenhou em sua trajetória, o que remete à observação de Antonio Viñao Frago (2007): “todos los viajes educan, aunque solo sea por abrir 
al viajero a una realidad diferente a la suya. Sólo que unos educan más que otros, o de forma diferente a otros" (p.15). Olhando para trás, ela inicia sua escrita dizendo "Dizem que a vida começa aos quarenta: a minha começou quando fiz a minha primeira viagem à Europa”, viagem esta que, segundo Andrea Caruso (op.cit), surgiu da necessidade de auxiliar a mãe - Isabel Jacobina Lacombe - na direção do Colégio Jacobina:

A família Jacobina, tendo consciência de que a jovem Laura ainda não estava preparada para substituir sua mãe no ofício de maior responsabilidade dentro instituição educacional, começo a pensar em uma solução plausível para que Laura pudesse descansar dessa função que tomava tanto seu tempo, principalmente a partir do crescimento do colégio nos últimos anos. Por isso, em 1924, Isabel Jacobina Lacombe cogitou em trazer uma professora da Europa para tomar conta do colégio, mas o amigo Carneiro Leão, diretor da Instrução Pública, sugeriu que ao invés de ela mandar vir alguém de fora, que mandasse Laura à Europa (2006, p. 58).

A decisão de ir para a Suíça talvez tenha se dado porque era o país considerado, segundo Jean Houssaye (2007), a Meca da pedagogia, pois “o imenso movimento da Educação Nova terá seu epicentro no Instituto Jean-Jacques Rousseau de Genebra” (idem, p. 305), onde os pedagogos ali reunidos atuaram fortemente na produção e difusão do ideário escolanovista como "grandes viajantes, fisicamente, intelectualmente e coletivamente" (idem, p. 298). Aliás, Rogério Fernandes quando se detém na relação estabelecida por educadores portugueses com aquele instituto suíço, assinala que ele se constituía em "principal centro de produção da teoria da escola nova", fazendo com que Faria de Vasconcelos, fundador de uma escola nova, na Bélgica, após a guerra de 1914-1918, se retirasse para Genebra, o que tanto o aproximou de Edouard Claparède e Adolphe Ferrière, quanto lhe permitiu ser "convidado mais tarde a contribuir à difusão desta corrente pedagógica na América Latina, designadamente em Cuba e na Bolívia, onde liderou reformas escolares" (FERNANDES, 2007, p 218). Martha Chagas de Carvalho, por sua vez, chama a atenção para o papel desempenhado por A. Ferrière na difusão do escolanovismo, quando se dedica ao exame da revista Pour l'Ere Nouvelle, órgão francófono da Ligue International de la Education Nouvelle, fundada em 1921, por ocasião do I Congresso Internacional de Educação Nova, em Calais, promovido pelo New Educational Felowship e pelo Bureau International dés Écoles Nouvelles, por ele criado, em 1899, e que, em 1926, passaria a ser o departamento internacional do Instituto Jean-Jacques Rousseau, visando "estabelecer relações de cooperação científica entre diferentes Escolas Novas e centralizar a documentação" (Carvalho, 2007, p. 282). Ainda segundo a autora, por esta revista, que dividia com a The New 
Era e Das Werdenda Zeitalter, inglesa e alemã, respectivamente, o papel de porta voz da Liga, em especial, como órgão responsável pelos contatos com a América Latina, os relatos de viagens ganhavam espaço na medida em que propagavam o sucesso do movimento que pretendia fazer da escola um importante espaço de transformação social, especialmente a partir de 1925, quando Ferrière assume a posição de redator chefe, Paul Faucounnet o de redator para a França, e Ovide Decroly o de redator para a Bélgica.

Detalhadamente, Laura lembra das salas do Instituto Jean-Jacques Rousseau onde se reuniam estudantes de várias partes do mundo, do relacionamento do educador com os alunos que testemunhou também em sua viagem a Locarno, dois anos depois, quando "mil e duzentos educadores de quarenta países, das cinco partes do mundo ali se reuniram" e os "professores Claparède e Bovet estavam sempre cercados de seus alunos e, fora das horas de trabalho, multiplicavam-se em excursões no lago. (...) Na volta de Locarno, minha irmã Mabel e eu passamos por Genebra e vivemos agradáveis momentos no 'Vieux Chample', onde fomos carinhosamente acolhidas pelo mestre Claparède", (LACOMBE, 1973, s/p) o que sinalizava uma intimidade com o educador, que prosseguiu durante muitos anos em cartas trocadas quando o filho dele morreu e que se confirma quando foi pessoalmente comunicada pela Mme Claparède e, em especial, por Pierre Bovet, do falecimento daquele que fora seu "mestre e amigo". Bovet lamentava que não existissem mais alunos da América do Sul no Intituto Jean-Jacques Rousseau, mas o professor Ferrière continuava ativo e generoso e Jean Piaget trabalhava mais do que nunca. Termina sua narrativa, na sessão comemorativa do centenário de nascimento de Edouard Claparède festejando o prosseguimento das atividades que testemunhara:

E é com prazer que vejo que o impulso lá tomado pelo então jovem Prof. Piaget, não esmoreceu até hoje, pois vai brilhantemente continuando a difundir e enriquecer a mensagem que o Institut Rousseau, hoje Institut de Sciences de l'Education, vem desde 1912 enviando ao mundo para promover uma pedagogia científica que atenda a uma formação profunda do conhecimento da criança, baseada na sua psicologia.

Foi, o Prof. Piaget, escolhido para substituir o Prof. Claparède na cátedra de Psicologia, e mais tarde assumiu a Direção do Institut, no falecimento do Prof. Bovet.

Assim, é ele quem está levando ao mundo todo, a tocha acesa em 1912. Em breve, teremos o prazer de recebê-lo na nossa cidade. Para quem teve a felicidade de participar daquela colmeia laboriosa, naquele centro onde todos formávamos uma família, é reviver um pouco aquele ambiente, é voltar, também, aos seus anos de juventude (LACOMBE, 1973, s/p). 


\section{A chegada do amigo ao Rio de Janeiro}

A amizade com o mestre não se restringiu aos encontros compartilhados na Suíça. $\mathrm{Na}$ sequência dos documentos reunidos por Laura Jacobina Lacombe, além de cartas trocadas com Claparède, Bovet e Mme Claparède, duas fotografias dão conta da viagem do mestre e amigo ao Rio de Janeiro em 1930: uma onde ele aparece sentado na mureta no alto do Corcovado e outra na qual está ladeado por Consuelo Pinheiro, Gustavo Lessa e pela própria Laura. Nas suas palavras,

Passaram-se os anos e veio Claparède ao Brasil. Tivemos o prazer de apresentar-lhe a nossa escola. Encheram-nos de alegria as suas palavras de animação. Ao sair, teve uma exclamação que até hoje nos soa aos ouvidos:

C'est mon école ideále, une grande famille... e pouco depois

On sent que le bonheur y règne! (LACOMBE, 1973, s/p)

Desta viagem do amigo, amplamente festejada na imprensa carioca por Cecília Meireles e Gerardo Seguel, quando foi recebido como "um educador notável”, fundador do Instituto JeanJacques Rousseau, juntamente com Ferrière, Bovet e Piaget, mas, sobretudo, aquele que desperta "no magistério universal o mesmo interesse que as questões da educação, como parte que são delas mesmas, encerrando o seu significado, a sua compreensão e explicação”. (Meireles,1930, p. 6) Laura ainda se lembraria dos comentários feitos por ele em carta em que agradecia seus votos de pêsames por ocasião da morte prematura do único filho, em 1937, e recordou dos "bons momentos da sua visita ao Brasil, quando teve a oportunidade de assistir a uma reunião de família em nossa casa, na qual festejávamos os 82 anos de nossa Vovózinha, com a presença de numerosos familiares”. (LACOMBE, 1973, s/p)

Esta viagem realizada na mesma época que Ferrière visitou a América do Sul, passando pelo Equador, Peru, Chile, Argentina, Paraguai e Uruguai, fazia parte das estratégias do Instituto Jean-Jacques Rousseau para estreitar laços, divulgar experiências e estabelecer novos contatos, legitimando-se, deste modo, como um "centro de referência", um "centro de investigações", um "centro de informações" e um "centro de propaganda" (Mignot, 2007, p.258). Laura lembra ainda do momento político do país, por ocasião da chegada do amigo:

Não podemos esquecer alguns detalhes da visita que o Prof. Claparède havia feito ao Brasil: ficara retido em Belo Horizonte quando estourou a revolução de 1930. Durante alguns dias sentiu-se angustiado por ter sido interrompida toda e qualquer comunicação com o resto do Brasil e do mundo. Contando-nos essa situação, exclamou: 
Et ces braves 'mineires' ne s'en souciaient même pas... (LACOMBE, $1973, \mathrm{~s} / \mathrm{p})$

A chegada de Adolphe Ferrière ao Rio de Janeiro, no entanto, segundo Marta Chagas de Carvalho, teve outras particularidades. Ele fora impedido de desembarcar no Brasil, pela eclosão da Revolução de 1930, mas registrou suas impressões da educação brasileira, a partir das publicações recebidas a bordo do navio ancorado. Seu relato da viagem, publicado na Pour L'Ere Nouvelle, permitiu à autora tecer algumas observações. Estranhou as leituras de Ferrière que conformaram suas impressões de viagem, ignorando as publicações da $A B E$, que provavelmente chegaram às suas mãos, dando particular acolhida as versões de Fernando de Azevedo e Deodato de Moraes sobre a educação brasileira, pois teve acesso à Revista Brasileira de Educação publicada pela Federação Nacional das Sociedades de Educação, que, desde o ano anterior, por iniciativa de Vicente Licínio Cardoso, estava em tratativas para se filiar à Liga. Problematizando estas escolhas, a autora lembra que, neste momento, a associação carioca estava sob a hegemonia do grupo católico. Por outro lado, assinala, talvez o grupo que controlava a entidade, naquele momento, não tivesse interesse em tal filiação visto que no Congresso Internacional de Educação Moderna, ocorrido em Locarno, em 1927, um bispo proibira a participação de fiéis. Mas, estranha ainda não haver, no relato do viajante, nenhuma alusão a Laura Jacobina Lacombe que representara a ABE naquele evento:

A participação de Laura Lacombe, no Congresso de Locarno, em 1927, e sua viagem à Suíça, onde fez curso no Institut Jean-Jacques Rousseau, excluem a possibilidade de que faltasse a Ferrière uma via de contato com a ABE. Membro muito ativo da Associação Brasileira de Educação, Laura Lacombe havia mesmo atuado como emissária do BIE na Primeira Conferência Nacional de Educação promovida pela ABE, em 1927, apresentando, no evento, uma memória sobre o Bureau que foi lida em Sessão Plenária. A leitura dessa memória teria mesmo ensejado a oportunidade de inúmeras novas adesões à instituição suíça, por intermédio de seu então correspondente brasileiro, Lourenço Filho (Carvalho, 2007, p. 289).

\section{Uma amizade feita de ciência e fé}

Mergulhada ainda na documentação organizada por Laura Jacobina Lacombe, na pasta Claparède, mestre e amigo, não escapa a ausência de uma referência mais alentada à obra do educador que chegara ao país com alguns livros publicados, nos quais expressava suas inquietações acerca das relações da Psicologia com a educação: Psicologia da criança $e$

Revista Interinstitucional Artes de Educar. Rio de Janeiro, V. 2, N. Especial - pag 253-265 (jun - out 2016): "Vozes da 
pedagogia experimental, A orientação profissional, Como diagnosticar as aptidões dos colegiais, A Psicologia experimental e a escola ativa, A associação dos ideais, Rousseau e a concepção funcional da infância e $A$ escola sob medida, muitas deles traduzidos em diversos idiomas, o que repercutiu na formação de psicólogos e educadores e na formulação de perspectivas teóricas com claras implicações na Pedagogia e na Psicologia contemporâneas, como observam Nassif e Campos (2005). Não há menção à palestra por ele proferida na $\mathrm{ABE}$, quando discorreu sobre "O sentimento de inferioridade na criança", enfatizando que este sentimento se fazia sentir na idade adulta, tanto pela timidez quanto pela falta de coragem para enfrentar a vida.

Em meio à leitura, ainda preliminar do vivido, narrado e guardado, percebo que Laura selecionou o que contar, destacando no texto e em documentos que se seguiram, a bondade que ele tivera para que "percorresse, página por página, o livro do escritor e caricaturista suíço Töpffer, Histoire de Monsieur Crépin, onde é feita uma crítica da psicologia da época em que se propagava a teoria das localizações cerebrais”. (LACOMBE, 1973, s/p) Não fez nenhuma referência às suas ressalvas à Escola Ativa, como consta do relatório de viagem, manuscrito, apresentado ao Conselho Diretor da ABE, quando voltou de Locarno:

Os princípios da "escola ativa" tão bem estudados pelo Prof. Ferrière nos seus livros, merecem ser aprofundados para serem adotados em nosso país a exemplo do que já fez a Áustria. (...)

Verdade é que esses métodos precisam ser adaptados à nossa raça para serem eficientes pois se não forem bem empregados serão até prejudiciais. Se a liberdade não for bem dosada cai-se na anarquia, o que talvez seja pior do que a disciplina antiga.

Em resumo: a "escola ativa" é o remédio contra a educação livresca que desenvolve a memória do aluno, considerando-o apenas um corpo receptor, sem lhe aproveitar as qualidades que o farão vencer na vida.

É preciso desde cedo acostumar a criança com o sentimento de responsabilidade, começando por the confiar encargos materiais, passando mais tarde aos morais. (Lacombe, 1927, pp. 11 e 12).

Preferiu demonstrar, para além da admiração, os laços de afeto que os uniam e que lhe permitiram, por ocasião da morte do filho, presentear o amigo com dois livros católicos sobre o sofrimento, que teriam levado Claparède a agradecer em carta a emoção causada pela lembrança e palavras de conforto que serviram de consolo a ele e à sua mulher. Este foi o modo de Laura Jacobina Lacombe para reavivar a memória de todos de que teria sido ela o principal elo de ligação da ABE com o Instituto Jean-Jacques Rousseau e de reafirmar sua fé, na sessão solene promovida pela associação, em homenagem ao mestre e amigo. Talvez, isto encontre justificativa na análise de Marta Chagas de Carvalho (2002) quando lembra que diferentemente 
do que se tem acreditado, a militância católica não se opôs ao avanço das novas propostas pedagógicas e se mobilizou para difundir "a sua versão da nova pedagogia”, por intermédio de congressos, cursos, conferências, boletins e revistas, a fim de "regrar a sedução exercida pelo escolanovismo sobre o professorado", sedução esta que atingiu "não somente as práticas dos professores das escolas católicas, mas também do professorado católico nas escolas públicas" (op.cit. p. 390).

A leitura de Claparede, mestre e amigo, que não se esgota aqui, me permitiu ter acesso a um particular relato, repleto de silêncios, omissões e invenções, revelador tanto do lugar social da viajante e do contexto das viagens quanto de concepções e crenças que guiaram o olhar e moveram a escrita das memórias de travessias desta educadora.

\section{Referências bibliográficas}

ASSOCIAÇÃO BRASILEIRA DE EDUCAÇÃO, Ata do Conselho Diretor. novembro de 1931. CARDOSO, Silmara de Fátima. Viajar é ser autor de muitas histórias: experiências de formação e narrativas educacionais de professores brasileiros em viagem aos Estados Unidos (1929-1935). São Paulo: Universidade de São Paulo, Programa de Pós-Graduação em Educação (tese de doutorado), 2015.

CARUSO, Andrea Soares. Traço de união como vitrine: educação feminina, ideário católico e práticas escolanovistas no periódico do Colégio Jacobina. Rio de Janeiro: Universidade do Estado do Rio de Janeiro, Programa de Pós-graduação em Educação (dissertação de mestrado), 2006.

CARVALHO, Marta Chagas de. A bordo do navio, lendo notícias do Brasil: o relato de viagem de Adolphe Ferrière In. MIGNOT, Ana Chrystina; GONDRA, José (orgs). Viagens Pedagógicas. São Paulo: Cortez Editora, 2007. pp. 277-293.

CARVALHO, Marta Chagas de. Pedagogia da Escola Nova, produção da natureza infantil e controle doutrinário da escola. In. FREITAS, Marcos Cezar de; KUHLMAN, Moysés (orgs). Os intelectuais na história da infância, Cortez Editora, 2002, pp. 373-408.

CARVALHO, Marta Chagas de. Molde nacional e fôrma cívica: higiene, moral e trabalho no projeto da Associação Brasileira de Educação. Bragança Paulista: EDUSF, 1998.

FERNANDES, Rogério. Irene Lisboa e Alda Judite Amaral: dois olhares sobre a escola a partir da 'Escola Nova' In. MIGNOT, Ana Chrystina; GONDRA, José (orgs). Viagens Pedagógicas. São Paulo: Cortez, 2007. pp. 217-243.

HOUSSAYE, Jean. In. Pedagogias: importação-exportação. MIGNOT, Ana Chrystina; GONDRA, José (orgs). Viagens Pedagógicas. São Paulo: Cortez, 2007. pp. 294-314.

LACOMBE, Laura Jacobina. Claparède, mestre e amigo. Arquivo da Associação Brasileira de Educação. (dat), 1973.

. Relatório do Congresso de Educação Moderna - Locarno (manuscrito). Arquivo da Associação Brasileira de Educação. (manuscrito) 1927.

. Discurso na OMEP. OMEP, (datilografado) 1970.

LOURENÇO FILHO, Manuel Bergson. Introdução ao estudo da Escola Nova. São Paulo: Melhoramentos, $12^{\mathrm{a}}$ ed., 1962

MEIRELES, Cecília. A visita de um pedagogo notável, Rio de Janeiro: Diário de Notícias, 1930, p. 6 .

Revista Interinstitucional Artes de Educar. Rio de Janeiro, V. 2, N. Especial - pag 253-265 (jun - out 2016): "Vozes da Educação" 
MIGNOT, Ana Chrystina. Baú de memórias, bastidores de histórias: o legado pioneiro de Armanda Alvaro Alberto. Bragança Paulista: EDUSF, 2002.

. Entre cartas e cartões postais: uma inspiradora travessia. In. MIGNOT, Ana Chrystina; GONDRA, José (orgs). Viagens Pedagógicas. São Paulo: Cortez, 2007. pp. 246-276.

NASSIF, Lilian E.; CAMPOS, Regina Helena de F. Edouard Claparède (1870-1940): interesse, afetividade e inteligência na concepção da psicologia funcional. In. Memorandum, Belo Horizonte, v.9. 2005, pp. 91-104.

STANG, Bernanete de Lourdes Streisky. O saber e o credo: os intelectuais católicos e a doutrina da Escola Nova (1924-1940). Rio de Janeiro: Pontifícia Universidade Católica do Rio de Janeiro. Programa de Pós-Graduação em Educação (tese de doutorado), 2008.

VINÃO FRAGO, Antonio. Las autobiografias, memorias y diarios como fuente históricoeducativa: tipologias y usos. Rio de Janeiro: Teias, vol 1, n 1, 2000, pp. 82-97.

. Viajes que educan. In. MIGNOT, Ana Chrystina; GONDRA, José (orgs). Viagens

Pedagógicas. São Paulo: Cortez, 2007. pp. 15-38.

i A respeito desta Seção de Cooperação da Família, consultar particularmente Carvalho (1998 ) e Mignot (2002).

ii Isabel Jacobina Lacombe, Maria Amélia Lacombe, Américo Lacombe, Amélia Rezende, Eliza Rezende, Décio Lyra, dentre outros.

iii Segundo Caruso (2006), influenciada pelo padre Arthur Alonso, de quem era secretária, Laura Jacobina Lacombe se une a Nise Cardoso, Everardo Backheuser, Madre M.S. Luis Gonzaga Cintra, Madre Maria de Jesus Medeiros, Lourenço Filho, Sara Dawsey e Madre Mikeal, sob a direção de Mme Herbeniere Lebert, presidente da OMEP da França, para fundar a entidade. 